\title{
Multi-platform multimedia data analysis and modeling
}

(C) Springer Science+Business Media, LLC, part of Springer Nature 2020

Multimedia Tools and Applications gratefully acknowledges the editorial work of the scholars listed below on the special issue entitled "Multi-platform Multimedia Data Analysis and Modeling" (SI 1108).

Of 30 papers submitted to this issue, 12 were eventually accepted after a stringent peer review process.

\section{Corresponding Guest Editor}

\section{Dr Xueliang Liu}

Hefei University of Technology, China

Email: liuxueliang@hfut.edu.cn

\section{Guest Editors}

\section{Dr Hanwang Zhang}

Nanyang Technological University, Singapore

Email: hanwangzhang@ntu.edu.sg

Dr Benoit Huet

EURECOM, France

Email: huet@eurecom.fr

Publisher's note Springer Nature remains neutral with regard to jurisdictional claims in published maps and institutional affiliations. 